\title{
Analysis of the Relationship Between ADIPOR1 Variants and the Susceptibility of Chronic Metabolic Diseases in a Northeast Han Chinese Population
}

\author{
Fengling Wang, ${ }^{1,2,{ }^{*}}$ Shuzhen Suo, ${ }^{1,3,{ }^{*}}$ Liang Sun, Jun Yang, ${ }^{4}$ Fan Yang, ${ }^{1}$ Chengxiao Zhao, ${ }^{1}$ Xuejie Li, ${ }^{3}$ \\ Ludan Yuan, ${ }^{3}$ Shuqian Yu, ${ }^{3}$ Tao Qi, ${ }^{3}$ Xiaoquan Zhu, Huiping Yuan,' Zening Jin,, \\ Lianmei Pu, ${ }^{5}$ Deping Liu, ${ }^{1}$ Xiaofang Sui, ${ }^{2}$ and Ze Yang ${ }^{1}$
}

Objective: Shared genetic variants in ADIPORI have been identified as closely related to coronary artery disease (CAD), type 2 diabetes (T2D), and T2D with CAD susceptibility, suggesting that these variants are strong candidates for the common soil hypothesis. Therefore, it is essential to analyze the relationship between ADIPORI variants and the susceptibility to $\mathrm{CAD}, \mathrm{T} 2 \mathrm{D}$, and $\mathrm{T} 2 \mathrm{D}$ with $\mathrm{CAD}$ in other populations. Materials and Methods: A case-control study was conducted which included three case cohorts [CAD $(n=316)$, T2D $(n=295)$, T2D with CAD $(n=302)]$, and a control cohort $(n=268)$ from a population in northeast China. Six ADIPORl single-nucleotide polymorphisms were genotyped by high-resolution melting and polymerase chain reaction-restriction fragment length polymorphism. Results: We confirmed that the shared variant, rs $3737884 * \mathrm{G}$, in ADIPOR1 is associated with CAD, T2D, and T2D with CAD ( $p$-value range: 6.54E-6-1.82E5 , odds ratio [OR] range: $1.770-1.844$ ) and that $r 516850797 * \mathrm{C}$ is associated with T2D and T2D with CAD ( $p$-value range: $0.001-0.001$, OR range: $1.529-1.571$ ). We also found that a novel shared variant, rs $7514221 * \mathrm{C}$, is associated with an increased susceptibility to CAD, T2D, and T2D with CAD ( $p$-value range: $0.002-0.004$, OR range: $1.194-2.382$ ) in this population. Conclusions: ADPORI variants, rs $3737884 * \mathrm{G}$ and $\mathrm{rs} 7514221 * \mathrm{C}$, may be shared risk factors associated with CAD, T2D, and T2D with CAD in a population of northeast China.

\section{Introduction}

$\mathbf{C}$ ORONARY ARTERY DISEASE (CAD) and type 2 diabetes (T2D) are both chronic metabolic diseases triggered by several common factors and shared polygenic variants with high prevalence and morbidity (Alberti and Zimmet, 1998; King et al., 1998). To our surprise, CAD is the leading cause of mortality and morbidity in patients with T2D and accounts for up to $80 \%$ of deaths in patients with this disorder (Doria, 2010). It has been hypothesized that T2D and CAD share a common genetic basis (Dong et al., 2014), and the adiponectin signaling-related gene has been postulated to play critical roles in this scenario (Tao et al., 2014).

Adiponectin is a functionally active adipokine that regulates glucose and lipid metabolism. The metabolic effects and biological function of adiponectin are mainly mediated by adiponectin receptor 1 (ADIPOR1) (Kadowaki and Ya- mauchi, 2011). So, ADIPOR1 plays an important role in indirectly regulating glucose and lipid metabolism in chronic metabolic diseases (Yamauchi et al., 2014). The human ADIPOR1 gene is located at chromosome 1p36.13-q41 and presents several polymorphisms (Yamauchi et al., 2014). Some of these polymorphisms have been shown to be associated with an increased risk of developing several diseases, including obesity (Lacinov et al., 2007), metabolic syndrome (Peters et al., 2013), diabetes (Qi et al., 2007), cardiovascular disease (Cox et al., 2013), gastric cancer (Shin et al., 2013), colorectal cancer (Liu et al., 2011), and prostate cancer (Kaklamani et al., 2011). However, to the best of our knowledge, there is only one report to date on the association of ADIPOR1 variants with $\mathrm{CAD}, \mathrm{T} 2 \mathrm{D}$, and $\mathrm{T} 2 \mathrm{D}$ with $\mathrm{CAD}$ risk among the northern Han Chinese population (Jin et al., 2014). Due to differences of genetic background, gene variation association studies may vary among populations in

\footnotetext{
${ }^{1}$ The Key Laboratory of Geriatrics, Beijing Hospital \& Beijing Institute of Geriatrics, Chinese Ministry of Health, Beijing, China.

${ }^{2}$ Department of Geriatrics, ${ }^{4}$ Department of Cardiology, the First Affiliated Hospital of Jiamusi University, Jiamusi, China.

${ }^{3}$ Clinical Medical School, Jiamusi University, Jiamusi, China.

${ }^{5}$ Department of Emergency Medicine, Anzhen Hospital, Capital Medical University, Beijing Institute of Heart Lung and Blood Vessels, Beijing, China.

*These authors contributed equally to the work.

(C) Fengling Wang, et al., 2016; Published by Mary Ann Liebert, Inc. This Open Access article is distributed under the terms of the Creative Commons Attribution Noncommercial License (http://creativecommons.org/licenses/by-nc/4.0/) which permits any noncommercial use, distribution, and reproduction in any medium, provided the original author(s) and the source are credited.
} 
allele frequencies and linkage disequilibrium (LD) structures. It is important to examine multiple ethnic populations for the identification of ethnicity-specific loci as well as common susceptibility loci (Deschamps et al., 2015).

Therefore, we conducted a study assessing the association of $A D I P O R 1$ variants with CAD, T2D, and T2D with CAD in a northeast Han Chinese population. The study may lay a theoretical foundation for the common soil hypothesis.

\section{Materials and Methods}

\section{Ethics statement}

All participants agreed to the protocol of this study and provided written informed consent. The study protocol was approved by the local research ethics committee.

\section{Participants}

The study population included patients who self-identified as having a Han ethnic origin and permanent residents of the Jiamusi Heilongjiang area in northeast China. We enrolled a total of 1181 subjects containing 316 CAD, 295 T2D, and 302 T2D with CAD patients, as well as 268 healthy controls between October 2014 and May 2015. T2D was diagnosed according to World Health Organization criteria (Alberti and Zimmet, 1998), while classification of CAD patients was based on previous studies (Qi et al., 2013). The patients in the T2D with CAD group met both of the above inclusion criteria. The control group comprised healthy individuals who had no dyslipidemia and abnormal glucose tolerance, as well as family history of CAD or T2D in first-degree relatives. The exclusion criteria were the same as the criteria of the previous study (Jin et al., 2014).

Table 1. The Allele and Genotypic Frequencies of ADIPOR1 SNPs

\begin{tabular}{|c|c|c|c|c|c|c|c|c|}
\hline \multirow[b]{2}{*}{ SNP } & \multicolumn{2}{|c|}{ Control $(\mathrm{n}=268)$} & \multicolumn{2}{|c|}{$C A D(\mathrm{n}=316)$} & \multicolumn{2}{|c|}{$T 2 D(\mathrm{n}=295)$} & \multicolumn{2}{|c|}{$T 2 D$ with $C A D(\mathrm{n}=302)$} \\
\hline & $\mathrm{n}(\%)$ & $\mathrm{p}$ & $\mathrm{n}(\%)$ & $\mathrm{p} / O R(95 \% C I)$ & $\mathrm{n}(\%)$ & $\mathrm{p} / O R(95 \% C I)$ & $\mathrm{n}(\%)$ & $\mathrm{p} / O R(95 \% C I)$ \\
\hline \multicolumn{9}{|c|}{ rs7539542 } \\
\hline $\mathrm{C}$ & $199(37.1)$ & 0.784 & $220(34.8)$ & 0.410 & $215(36.4)$ & 0.81 & $210(34.8)$ & 0.407 \\
\hline $\mathrm{G}$ & $337(62.9)$ & & $412(65.2)$ & 0.904 & 375 (63.6) & 0.970 & $394(65.2)$ & 0.902 \\
\hline $\mathrm{CC}$ & $45(16.8)$ & 0.165 & $34(10.8)$ & $(0.711-1.149)$ & $36(122)$ & $(0.761-1.237)$ & 43 (14.2) & $(0.708-1.150)$ \\
\hline CG & 109 (40.7) & & $152(48.1)$ & 0.056 & $143(48.5)$ & 0.115 & $124(41.1)$ & 0.684 \\
\hline GG & $114(42.5)$ & & $130(41.1)$ & & $116(39.3)$ & & $135(44.7)$ & \\
\hline \multicolumn{9}{|c|}{ rs3737884 } \\
\hline G & $362(67.5)$ & $9.47 \mathrm{E}-7^{\mathrm{a}}$ & 497 (78.6) & $1.82 \mathrm{E}-5^{\mathrm{b}}$ & 468 (79.3) & $7.24 \mathrm{E}-6^{\mathrm{c}}$ & 479 (79.3) & $6.54 \mathrm{E}-6^{\mathrm{d}}$ \\
\hline A & $174(32.5)$ & & 135 (21.4) & 1.770 & $122(20.7)$ & 1.844 & $125(20.7)$ & 1.842 \\
\hline GG & $127(47.4)$ & $3.67 \mathrm{E}-7^{\mathrm{a}}$ & $198(62.7)$ & $(1.362-2.301)$ & $184(62.4)$ & $(1.409-2.413)$ & $192(63.5)$ & $(1.410-2.406)$ \\
\hline AG & $108(40.3)$ & & $101(32.0)$ & $2.00 \mathrm{E}-4^{\mathrm{b}}$ & $100(33.9)$ & $3.60 \mathrm{E}-5^{\mathrm{c}}$ & $95(31.5)$ & $8.00 \mathrm{E}-5^{\mathrm{d}}$ \\
\hline AA & $33(12.3)$ & & $17(5.3)$ & & $11(62.4)$ & & $15(5.0)$ & \\
\hline \multicolumn{9}{|c|}{ rs1342387 } \\
\hline A & $201(37.5)$ & 0.619 & $255(40.6)$ & 0.27 & $237(40.2)$ & 0.358 & & 0.873 \\
\hline G & $335(62.5)$ & & $373(59.4)$ & 1.139 & $353(59.8)$ & 1.118 & $371(62.0)$ & 1.019 \\
\hline AA & $43(16.1)$ & 0.688 & $57(18.2)$ & $(0.899-1.44)$ & $51(17.3)$ & $(0.880-1.422)$ & $41(13.7)$ & $(0.802-1.297)$ \\
\hline AG & $115(42.9)$ & & $141(44.9)$ & 0.057 & $135(45.8)$ & 0.608 & $145(48.5)$ & 0.394 \\
\hline GG & $110(41.0)$ & & $116(36.9)$ & & 109 (36.9) & & $113(37.8)$ & \\
\hline \multicolumn{9}{|c|}{ rs16850797 } \\
\hline $\mathrm{C}$ & $138(25.7)$ & $0.002^{\mathrm{a}}$ & $196(31.0)$ & 0.047 & $201(34.7)$ & $0.001^{\mathrm{c}}$ & $213(35.3)$ & $0.001^{\mathrm{d}}$ \\
\hline $\mathrm{G}$ & $398(74.3)$ & & $436(69.0)$ & 1.293 & 379 (65.3) & 1.529 & $391(64.7)$ & 1.571 \\
\hline $\mathrm{CC}$ & $21(7.8)$ & $0.001^{\mathrm{a}}$ & 47 (14.9) & $(1.002-1.675)$ & $36(12.4)$ & $(1.181-1.980)$ & 54 (17.9) & $(1.217-2.028)$ \\
\hline CG & $96(35.9)$ & & $102(32.3)$ & 0.029 & $129(44.5)$ & $0.005^{\mathrm{c}}$ & $105(34.8)$ & $0.001^{\mathrm{d}}$ \\
\hline GG & $151(56.3)$ & & $167(52.8)$ & & $125(43.1)$ & & $143(47.4)$ & \\
\hline \multicolumn{9}{|c|}{ rs12045862 } \\
\hline $\mathrm{C}$ & $248(46.3)$ & 0.05 & 324 (51.9) & 0.055 & $298(54.6)$ & 0.016 & $303(50.7)$ & 0.139 \\
\hline $\mathrm{T}$ & $288(53.7)$ & & $300(48.1)$ & 1.234 & $248(45.4)$ & 1.395 & $295(49.3)$ & 1.192 \\
\hline $\mathrm{CC}$ & $64(23.9)$ & 0.14 & $84(26.9)$ & $(0.995-1.580)$ & 87 (31.9) & $(1.098-1.772)$ & 79 (25.4) & $(0.944-1.506)$ \\
\hline CT & $120(44.8)$ & & $156(50.0)$ & 0.082 & $124(45.4)$ & 0.032 & $145(48.5)$ & 0.252 \\
\hline TT & $84(31.3)$ & & $72(23.1)$ & & $62(22.7)$ & & $75(25.1)$ & \\
\hline \multicolumn{9}{|c|}{ rs7514221 } \\
\hline $\mathrm{C}$ & 62 (11.6) & $0.013^{\mathrm{a}}$ & $111(17.6)$ & $0.004^{\mathrm{b}}$ & $106(18.0)$ & $0.002^{\mathrm{c}}$ & $110(16.6)$ & $0.002^{\mathrm{d}}$ \\
\hline $\mathrm{T}$ & $474(88.4)$ & & $521(82.4)$ & 1.629 & $484(82.0)$ & 1.674 & $494(83.4)$ & 1.702 \\
\hline $\mathrm{CC}$ & $5(1.9)$ & $0.017^{\mathrm{a}}$ & $9(2.8)$ & $(1.165-2.276)$ & $9(3.1)$ & $(1.194-2.347)$ & $13(2.3)$ & $(1.217-2.382)$ \\
\hline CT & $52(19.4)$ & & 93 (29.7) & 0.018 & $88(29.8)$ & $0.009^{c}$ & $84(26.8)$ & $0.010^{\mathrm{d}}$ \\
\hline TT & $211(78.7)$ & & $214(67.7)$ & & $198(67.1)$ & & $205(70.9)$ & \\
\hline
\end{tabular}

$p \leq 0.05 / 3=0.017 . n$ refers to number of individuals. Values are given as allele or genotype frequencies, proportions $(\%)$, and OR $(95 \%$ $\mathrm{CI}$ ); differences were compared using the Pearson's $\chi^{2}$ method.

${ }^{a}$ Significance indicates difference between case and control $p \leq 0.05$.

${ }^{\mathrm{b}}$ Significance indicates CAD versus control.

${ }^{\mathrm{c}}$ Significance indicates T2D versus control.

${ }^{\mathrm{d}}$ Significance indicates T2D with CAD versus control.

CAD, coronary artery disease; CI, confidence interval; OR, odds ratio; SNP, single-nucleotide polymorphism; T2D, type 2 diabetes. 
Table 2. Association Between Related ADIPOR1 SNPs and CAD, T2D, and T2D with CAD in Common Genetic Models

\begin{tabular}{|c|c|c|c|c|c|c|c|c|c|}
\hline \multirow[b]{2}{*}{ SNP } & \multicolumn{3}{|c|}{ CAD/control } & \multicolumn{3}{|c|}{$T 2 D /$ control } & \multicolumn{3}{|c|}{$C A D+T 2 D /$ control } \\
\hline & $\mathrm{p}$ & $O R$ & $95 \% C I$ & $\mathrm{p}$ & $O R$ & $95 \% C I$ & $\mathrm{p}$ & $O R$ & $95 \% C I$ \\
\hline \multicolumn{10}{|l|}{ rs3737884 } \\
\hline \multicolumn{10}{|l|}{ Codominant } \\
\hline GG & 3.39E-4 & 3.026 & $1.618-5.660$ & $2.02 \mathrm{E}-5$ & 4.346 & $2.118-8.919$ & $1.64 \mathrm{E}-4$ & 3.326 & $1.736-6.376$ \\
\hline GA & 0.068 & 1.815 & $0.952-3.450$ & 0.005 & 2.778 & $1.333-5.791$ & 0.051 & 1.935 & $0.991-3.784$ \\
\hline AA & $\mathrm{Rf}$ & - & - & Rf & - & - & $\mathrm{Rf}$ & - & - \\
\hline \multicolumn{10}{|l|}{ Dominant } \\
\hline $\begin{array}{l}\text { GG+GA } \\
\text { AA }\end{array}$ & 0.003 & 2.470 & $1.343-4.544$ & $1.51 \mathrm{E}-04$ & 3.626 & $1.793-7.330$ & 0.002 & 2.687 & $1.425-5.066$ \\
\hline $\begin{array}{l}\text { Recessive } \\
\text { GG } \\
\text { GA+AA }\end{array}$ & $2.14 \mathrm{E}-4$ & 1.863 & $1.338-2.593$ & 3.55E-04 & 1.84 & $1.315-2.576$ & $1.02 \mathrm{E}-04$ & 1.938 & $1.386-2.710$ \\
\hline \multicolumn{10}{|l|}{ rs16850797 } \\
\hline $\mathrm{CC}$ & 0.012 & 2.024 & $1.156-3.541$ & 0.014 & 2.071 & $1.150-3.729$ & $2.92 \mathrm{E}-4$ & 2.715 & $1.561-4.723$ \\
\hline CG & 0.025 & 0.961 & $0.674-1.370$ & 0.007 & 1.623 & $1.138-2.315$ & 0.432 & 1.155 & $0.807-1.654$ \\
\hline GG & $\mathrm{Rf}$ & - & - & Rf & - & - & Rf & - & - \\
\hline Dominant & & & & & & & & & \\
\hline $\begin{array}{l}\mathrm{CC}+\mathrm{CG} \\
\mathrm{GG}\end{array}$ & 0.398 & 1.151 & $0.830-1.597$ & 0.002 & 1.704 & $1.219-2.384$ & 0.032 & 1.435 & $1.031-1.997$ \\
\hline Recessive & & & & & & & & & \\
\hline $\begin{array}{l}\mathrm{CC} \\
\mathrm{CG}+\mathrm{GG}\end{array}$ & 0.008 & 2.055 & $1.194-3.536$ & 0.014 & 1.667 & $1.124-2.936$ & 3.98E-04 & 2.561 & $1.502-4.368$ \\
\hline \multicolumn{10}{|l|}{ rs7514221 } \\
\hline Codominan & & & & & & & & & \\
\hline $\mathrm{CC}$ & 0.305 & 1.775 & $0.585-5.383$ & 0.243 & 1.918 & $0.632-5.822$ & 0.057 & 2.676 & $0.937-7.641$ \\
\hline $\mathrm{CT}$ & 0.004 & 1.763 & $1.195-2.602$ & 0.003 & 1.803 & $1.216-2.674$ & 0.011 & 1.663 & $1.119-2.470$ \\
\hline $\mathrm{TT}$ & $\mathrm{Rf}$ & - & - & $\mathrm{Rf}$ & - & - & $\mathrm{Rf}$ & - & - \\
\hline $\begin{array}{l}\text { Dominant } \\
\text { CC+CT } \\
\text { TT }\end{array}$ & 0.003 & 1.764 & $1.212-2.569$ & 0.002 & 1.813 & $1.240-2.653$ & 0.004 & 1.752 & $1.199-2.560$ \\
\hline $\begin{array}{l}\text { Recessive } \\
\text { CC } \\
\text { CT+TT }\end{array}$ & 0.439 & 1.542 & $0.510-4.658$ & 0.367 & 1.655 & $0.548-5.002$ & 0.097 & 2.366 & $0.832-6.727$ \\
\hline
\end{tabular}

Values are given as OR and $95 \%$ CI. Differences were compared by Pearson's $\chi^{2}$ test. $p \leq 0.017$ was considered to be statistically significant.

\section{Genotyping}

Six single-nucleotide polymorphisms (SNPs) (rs7539542, rs3737884, rs1342387, rs16850797, rs12045862, and rs7514221) on chromosome 1q32 were selected for genotyping in the present study. Genomic DNA was extracted from frozen EDTA whole peripheral blood using a salting-out procedure. The SNPs were genotyped using the polymerase chain reaction-restriction fragment length polymorphism method, with the exception of rs12045862, which was genotyped using high-resolution melting curves-unlabeled probe genotyping analysis. To ensure the quality of genotyping, we selected randomly three samples of each genotype to be directly sequenced. No discrepancies were observed.

\section{Statistical analyses}

The statistical analyses were performed using SPSS version 17.0 software. Continuous parameters were presented as mean \pm standard deviation (SD) and were compared using one-way analysis of variance (ANOVA). The normality of distributions of the continuous variables was assessed with the KolmogorovSmirnov test. Categorical data were given as proportions of all the samples and were compared using the Pearson's chi-square $\left(\chi^{2}\right)$ test. The odds ratios (ORs) and $95 \%$ confidence interval (CI) were calculated to evaluate the strength of association between variables. Hardy-Weinberg equilibrium (HWE) was verified using a chi-square goodness-fit test. Pairwise LD and haplotype analysis were confirmed using the open-source software, SHEsis. Bonferroni correction was conducted for multiple comparisons. A two-tailed value of $p \leq 0.05$ was considered to be statistically significant.

\section{Results}

\section{Clinical characteristics}

The prevalence of known chronic metabolic risk factors, including SBP, DBP, FBG, TG, TC, and LDL-C, appeared to be higher in each subgroup (CAD group, T2D group, and 
Table 3. Haplotype Analysis for ADIPOR1 SNPs and CAD, T2D, and T2D with CAD

\begin{tabular}{|c|c|c|c|c|c|c|}
\hline Haplotype & Case freq & Control freq & $\chi^{2}$ & $\mathrm{p}$ & $O R$ & $95 \% C I$ \\
\hline \multicolumn{7}{|c|}{ CAD versus control } \\
\hline A C T & $15.21(0.024)$ & $24.56(0.148)$ & 4.046 & 0.044 & 0.518 & $0.271-0.994$ \\
\hline $\mathrm{A} \mathrm{G} \mathrm{T}$ & $114.23(0.181)$ & $147.70(0.003)$ & 14.404 & $1.49 \mathrm{E}-4$ & 0.585 & $0.443-0.773$ \\
\hline $\mathrm{G} \mathrm{C} \mathrm{T}$ & $163.56(0.259)$ & $101.55(0.189)$ & 8.535 & 0.003 & 1.518 & $1.146-2.011$ \\
\hline G G C & $90.74(0.144)$ & $49.96(0.093)$ & 7.300 & 0.007 & 1.652 & $1.145-2.385$ \\
\hline C G T & $228.00(0.361)$ & $200.19(0.106)$ & 0.106 & 0.745 & 0.961 & $0.755-1.222$ \\
\hline \multicolumn{7}{|c|}{ T2D versus control } \\
\hline $\mathrm{A} \mathrm{C} \mathrm{T}$ & $20.54(0.035)$ & $24.56(0.046)$ & 0.745 & 0.387 & 0.769 & $0.423-1.399$ \\
\hline A G T & $100.36(0.173)$ & $147.70(0.276)$ & 16.652 & 4.54E-5 & 0.552 & $0.414-0.736$ \\
\hline $\mathrm{G} \mathrm{C} \mathrm{T}$ & $164.34(0.018)$ & $101.55(0.068)$ & 14.026 & $1.82 \mathrm{E}-4$ & 1.711 & $1.290-2.270$ \\
\hline G G C & $88.84(0.153)$ & $49.96(0.093)$ & 9.440 & 0.002 & 1.774 & $1.227-2.567$ \\
\hline C G T & $189.76(0.327)$ & $200.19(0.373)$ & 2.448 & 0.117 & 0.820 & $0.640-1.051$ \\
\hline \multicolumn{7}{|c|}{ T2D with CAD versus control } \\
\hline A C T & $25.26(0.042)$ & $24.56(0.046)$ & 0.095 & 0.758 & 0.915 & $0.518-1.614$ \\
\hline A G T & $94.28(0.156)$ & $147.70(0.276)$ & 23.773 & $1.10 \mathrm{E}-6$ & 0.489 & $0.366-0.654$ \\
\hline G C T & $164.02(0.272)$ & $101.55(0.189)$ & 11.088 & $8.74 \mathrm{E}-4$ & 1.608 & $1.214-2.130$ \\
\hline G G C & $68.10(0.113)$ & $49.96(0.093)$ & 1.242 & 0.265 & 1.245 & $0.847-1.830$ \\
\hline G G T & $225.43(0.373)$ & $200.19(0.373)$ & 0.004 & 0.947 & 1.008 & $0.792-1.283$ \\
\hline
\end{tabular}

All those with frequency $<0.03$ in both the case and control were excluded from the analysis. Pearson's $\chi^{2}$ analysis was performed; a significance level was set at $p \leq 0.05$.

T2D with CAD group), while HDL-C was lower compared with the normal control $(p>0.05)$.

\section{SNP association analysis}

We analyzed all SNPs and found a week pairwise LD for those SNPs. The observed genotype frequencies of the six polymorphisms conformed to the HWE in the control $(p>0.05)$. The allele and genotypic frequencies are shown in Table 1 . The $\mathrm{G}$ allele frequency for rs3737884 of each case subgroup (CAD, $\mathrm{T} 2 \mathrm{D}$, and T2D with CAD patients) was higher [ $p=1.82 \mathrm{E}-5$, $\mathrm{OR}=1.770,95 \%$ CI $(1.362-2.301) ; p=7.24 \mathrm{E}-6, \mathrm{OR}=1.844$, 95\% CI (1.409-2.413); $p=6.54 \mathrm{E}-6, \quad \mathrm{OR}=1.842,95 \%$ CI (1.410-2.406)] compared with the control. However, the C allele for rs 16850797 only conferred risk for the T2D and T2D with CAD groups $[p=0.001, \mathrm{OR}=1.529,95 \%$ CI $(1.181-$ $1.980) ; p=0.001, \mathrm{OR}=1.571,95 \%$ CI (1.217-2.028)]. In addition, the allele $\mathrm{C}$ of rs7514221 was also positively associated with the three diseases $[p=0.004, \mathrm{OR}=1.629,95 \% \mathrm{CI}$ (1.165-2.276); $p=0.002, \mathrm{OR}=1.674,95 \% \mathrm{CI}(1.194-2.347)$; $p=0.002, \mathrm{OR}=1.702,95 \% \mathrm{CI}(1.217-2.382)]$.

Through genetic model analysis, we found that rs $3737884 * \mathrm{G}$, rs $16850797 * \mathrm{C}$, and $\mathrm{rs} 7514221 * \mathrm{C}$ are risk variants for CAD, $\mathrm{T} 2 \mathrm{D}$, and T2D with CAD in at least one of the three genetic models (Table 2, $p<0.017$ ).

Haplotype GCT, which contains $3737884 * \mathrm{G}$, rs $16850797 * \mathrm{C}$, and $\mathrm{rs} 7514221^{*} \mathrm{~T}$, was the most prevalent risk haplotype for patients with CAD, T2D, and T2D with CAD (Table 3, $p<0.017$ ).

\section{Discussion}

ADIPOR1 variant, $\mathrm{rs} 3737884 * \mathrm{G}$, was associated with the susceptibility of CAD, T2D, and T2D with CAD, but rs $16850797^{*} \mathrm{C}$ was associated with T2D and T2D with CAD, which has only been reported in a northern Han Chinese population (Jin et al., 2014). There are different effects of genetics backgrounds on the disease in different ethnic groups, so an estimate of genetic effect size from one genetic background is frequently biased and more precise estimates can be obtained in independent replication study. Therefore, we conducted a replication study to assess the association of ADIPOR1 variants with T2D, CAD, and T2D with CAD in a northeast Han Chinese population.

Consistent with the above findings, we also identified a novel shared variant $\mathrm{rs} 7514221^{*} \mathrm{C}$ in ADIPOR1 that is associated with CAD, T2D, and T2D with CAD susceptibility in our study. Our finding confirms that ADPOR1 variant, rs $3737884^{*} \mathrm{G}$, is a strong shared candidate for the three diseases in a Chinese Han population. SNP rs $7514221^{*} \mathrm{C}$ seems to be also a shared genetic variant of CAD, T2D, and T2D with CAD in our study population. Considering that this is the first study on the shared variant rs7514221, it should be verified in other populations.

Although $\operatorname{rs} 16850797 * \mathrm{C}$ was just associated with T2D and T2D with CAD, our haplotype analysis showed that GCT containing two risk variants (rs3737884*G and $\mathrm{rs} 16850797 * \mathrm{C}$ ) was the most prevalent at-risk haplotype for the three diseases. It seems to suggest that we should pay attention to the integrity of the gene when we try to identify the genetic variation associated with diseases (Hannou et al., 2015).

The mechanisms through which variations in the ADIPOR 1 could influence CAD and T2D are only hypothetical at the moment. We suppose the two polymorphisms (rs3737884 and rs7514221) located inside intron of the ADIPORI locus could influence adiponectin receptor expression levels and further physiologically modulate adiponectin metabolic activities in distal metabolically active tissues (Luo et al., 2013).

However, we focused only on SNPs; numerous factors act individually and together to influence risk of the three diseases. So, we should involve more factors in our future work. Besides, further physiological and functional studies are also needed to reveal the molecular mechanisms and pathways underlying the associations with the three diseases (Ghanbari et al., 2015). 


\section{Conclusion}

Taken together, our study not only confirmed that $A D$ PORl variant, rs $3737884^{*} \mathrm{G}$, was a strong shared risk variant for CAD, T2D, and T2D with CAD but also identified a novel risk factor, rs $7514221 * \mathrm{C}$, shared with the three diseases in a population of northeast China.

\section{Acknowledgments}

The authors are thankful to all of the healthy volunteers and subjects who participated in this study and thank all of the nurses of the First Affiliated Hospital of Jiamusi University for collecting specimens and clinical information. The authors appreciate Jiancai Du and Xinghui Li from the Key Laboratory of Geriatrics, Beijing Hospital and Beijing Institute of Geriatrics, for dealing with writing problems, experiments, and experimental dates.

This study was funded by the Natural Science Foundation of China (81061120527, 81370445, 81472408, 81400790, 81571385), the National Department Public Benefit Research Foundation by the Ministry of Health P.R. China (201302008), Beijing Nova Program (Z121107002512058), 12th 5-Year National Program from the Ministry of Scientific Technology (2012BAI10B01), Graduate Science and Technology Innovation Projects in Jianusi University (LM2015-015), the General Program of Heilongjiang Province Natural Science Foundation of China (H2015076), and Heilongjiang Province Traditional Chinese Medicine Science and Technology Attack Project for the young and middle-aged people (ZQG-055).

\section{Author Disclosure Statement}

No competing financial interests exist.

\section{References}

Alberti KG, Zimmet PZ (1998) Definition, diagnosis and classification of diabetes mellitus and its complications. Part 1: diagnosis and classification of diabetes mellitus provisional report of a WHO consultation. Diabet Med 15:539-553.

Cox AJ, Lambird JE, Sandy An S, et al. (2013) Variants in adiponectin signaling pathway genes show little association with subclinical CVD in the diabetes heart study. Obesity (Silver Spring) 21:E456-E462.

Deschamps CL, Connors KE, Klein MS, et al. (2015) The ACTN3 R577X polymorphism is associated with cardiometabolic fitness in healthy young adults. PLoS One 10:e130644.

Dong C, Tang L, Liu Z, et al. (2014) Landscape of the relationship between type 2 diabetes and coronary heart disease through an integrated gene network analysis. Gene 539:30-36.

Doria A (2010) Genetics of diabetes complications. Curr Diab Rep 10:467-475.

Ghanbari M, Franco OH, de Looper H, et al. (2015) Genetic variations in miRNA binding sites affect miRNA-mediated regulation of several genes associated with cardiometabolic phenotypes. Circ Cardiovasc Genet 8:473-486.

Hannou SA, Wouters K, Paumelle R, et al. (2015) Functional genomics of the CDKN2A/B locus in cardiovascular and metabolic disease: what have we learned from GWASs? Trends Endocrinol Metab 26:176-184.

Jin Z, Pu L, Sun L, et al. (2014) Identification of susceptibility variants in ADIPOR1 gene associated with type 2 diabetes, coronary artery disease and the comorbidity of type 2 diabetes and coronary artery disease. PLoS One 9:e100339.
Kadowaki T, Yamauchi T (2011) Adiponectin receptor signaling: a new layer to the current model. Cell Metab 13:123-124.

Kaklamani V, Yi N, Zhang K, et al. (2011) Polymorphisms of ADIPOQ and ADIPOR1 and prostate cancer risk. Metabolism 60:1234-1243.

King H, Aubert RE, Herman WH (1998) Global burden of diabetes, 1995-2025: prevalence, numerical estimates, and projections. Diabetes Care 21:1414-1431.

Lacinov Z, Michalsk D, Kasalick M, et al. (2007) The influence of obesity on the gene expression of adiponectin and its receptor in subcutaneous adipose tissue. Vnitr Lek 53:11901197.

Liu L, Zhong R, Wei S, et al. (2011) Interactions between genetic variants in the adiponectin, adiponectin receptor 1 and environmental factors on the risk of colorectal cancer. PLoS One 6:e27301.

Luo N, Chung BH, Wang X, et al. (2013) Enhanced adiponectin actions by overexpression of adiponectin receptor 1 in macrophages. Atherosclerosis 228:124-135.

Peters KE, Beilby J, Cadby G, et al. (2013) A comprehensive investigation of variants in genes encoding adiponectin (ADIPOQ) and its receptors (ADIPOR1/R2), and their association with serum adiponectin, type 2 diabetes, insulin resistance and the metabolic syndrome. BMC Med Genet 14:15.

Qi L, Doria A, Giorgi E, et al. (2007) Variations in adiponectin receptor genes and susceptibility to type 2 diabetes in women: a tagging-single nucleotide polymorphism haplotype analysis. Diabetes 56:1586-1591.

Qi L, Qi Q, Prudente S, et al. (2013) Association between a genetic variant related to glutamic acid metabolism and coronary heart disease in individuals with type 2 diabetes. JAMA 310:821-828.

Shin E, Park DJ, Kim H, et al. (2013) Adiponectin receptor expression in gastric carcinoma: implications in tumor development and progression. J Cancer Res Clin Oncol 139: 709-718.

Tao C, Sifuentes A, Holland WL (2014) Regulation of glucose and lipid homeostasis by adiponectin: effects on hepatocytes, pancreatic $\beta$ cells and adipocytes. Best Pract Res Clin Endocrinol Metab 28:43-58.

Yamauchi T, Iwabu M, Okada M, et al. (2014) Adiponectin receptors: a review of their structure, function and how they work. Best Pract Res Clin Endocrinol Metab 28:15-23.

Address correspondence to: Xiaofang Sui, MD

Department of Geriatrics The First Affiliated Hospital of Jiamusi University 384 Dexiang Street Jiamusi 154002 China

E-mail: fucongtianjiang@163.com

Ze Yang, PhD The Key Laboratory of Geriatrics Beijing Hospital \& Beijing Institute of Geriatrics Chinese Ministry of Health 1 Dahua Road Dong Dan Beijing 100730

China

E-mail: yang_ze@sina.com 